\title{
An Epidemiologic Study of the Process of Changes in Anthropometric Indices in Children Under 24 Months Based on Gender Differences in Kohgiluyeh and Boyer Ahmad Province, Southwest Iran 2017-18: an Incidental Phenomenon or a Gender Inequality?
}

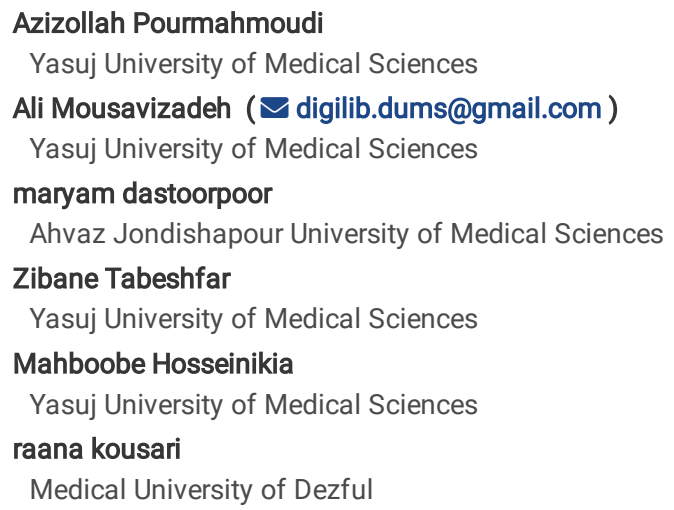




\section{Abstract}

\section{Background:}

An assessment of the process of changes in growth indices of children basaed on gender differences not only does provide the required information of the child's growth pattern, rather it also prepares the ground for a dynamic comparison of gender differences as a sensitive indicator of gender discrimination. The current research has been designed and implemented for depicting the growth patterns of children under two years old.

\section{Methods:}

Through a secondary analysis based study, the health files of 1336 children under 2 years old (700 boys and 636 girls) in the maternal and child health care system in Kohkiluyeh and Boyer Ahmad Province in 2017 were analyzed in terms of the nutritional status and in view of underweight and skinniness (wasting) and stunting (stunted growth) based on WHO standardization indicators.

\section{Results:}

The average difference of weight, height and head circumference of male and female children in the early days of their birth were respectively $67 \mathrm{~g}$, 0.36 and $0.37 \mathrm{~cm}$. Although z standardized score charts for average weight, height, and head circumference did not show a significant difference in the course of twoyear period among boys and girls, the percentage ratio of boys as compared to girls in low weight at birth, six months, one year and two years old are respectively $0.98,1.7,12.4$ and 1.5 for weight loss index $2.4,1.73,2.9$ and 1.9 , and for the short height (stunted growth) indexes $1.3,1.48,1.4$ and 1.6 , and for the head circumference index $0.48,2.27,1.56$ and 1.6 , and these indicate a constant gap between the boys with low weight, skinny and low head circumference measure and girls.

\section{Discussion and conclusion:}

In spite of the closeness of weight, height and head circumference differences in newborn girls and boys, their growth difference over the two-years period was associated with boys' superiority. In other words, boys had a more desirable growth trend than girls in terms of averaging indices. On the other hand, the percentage of male children with low weight, wasting and short height in the whole course of the study was more than female subjects. The research findings not only lay an emphasis on the gap between boys and girls in view of the studied indices, but also underlines the fact that in epidemiological studies, comparisons of averages are not an appropriate approach for comparing populations, and this in turn reveals the urgent need to pay more attention to frequency-based indicators. The recent attitude shift that has occurred among Iranian familes in terms of giving much care to girls as compared to boys against the previous inverted approach seems to be one of the most important justifications for this difference in growth trend.

\section{Background}

The first two years of birth are regarded as one of the most sensitive periods of life, which, in addition to its periodical importance, is also of a predictive value. The importance of this period is to such an extent that the mortality rate of children under one year is considered to be one of the most important indicators of the development of societies. Besides displaying the nutritional status of a child, growth monitoring can play a vital role in the diagnosis of growth impairment and diseases with nutritional basis in the early stages of life [1,2].

The studies that have been conducted regarding the growth indices show improvements in these indicators over the past decades. Mercedes de onis et al. have detected a declining trend in the underweight index in the East Asian region between 1999 and 2015 [3]. The improvement of mortality rate in the general infant population and sucklings in Iran is an alternative evidence that substantiates this claim [4-6]. Despite the observed improvement, attention to gender differences is another important point that might be forgotten in light of the overall improvement of the indicators. Differences that are sometimes inevitable and in some cases can be avoided (including health inequality). On the other hand, the study of the growth indices trend based on gender differences versus spot attitude, will be able to show the differences with a more reliable approach. Current research was designed due to the lack of a comprehensive report on the growth indices of children under two years within a two-years period in the study area, and was implemented via comparing standardized indicators in male and female children to explain the possible differences.

\section{Methods}

The research area with a population of about 700,000 and an area of 16,249 square kilometers is located in the southwest of Iran, and is home to roughly 1 percent of the population and the country's total area. With an average birth rate of $0.76 \%$, almost 10,000 new births are annually registered in this region. Sex ratio at birth is 1.2 and in the general population is one [7].

The current research has been designed as a secondary analysis of the information of health files of 1336 children under 2 years in the maternal and child health care system in 2017. Study protocol was approved by the Ethic Committee of the School of Public Health,Yasuj University of medical sciences (Ir.yums.REC.1394.78).The records were selected randomly from the record files of health homes and centers of the province keeping the balance between the urban and rural population ratios. Those records with did have more than $10 \%$ lost data and their completion was not possible were excluded.

Data collection tools that have been used in this research include observation forms (checklists) and, in necessary cases, interviews with the mothers of these children. In Primary Care System, weighing is done in terms of grams (with $100 \mathrm{~g}$ accuracy), height and head circumference are measured based on centimeter (with half $\mathrm{cm}$ precision) and using standard instruments of the Islamic Republic of Iran's care system and the measurement is conducted by experienced care experts. 
The collected data were processed by spss software and the standard anthropometric indices based on the formulas provided by the World Health Organization according to the $Z$ score and the final classification based on three indicators of weight for age, weight for height and height for age, respectively describing LBW, stunting, and short height, were analyzed according to formulas 1 to 10 as follows [8- 12].

Z score or standard diviation classification system:

equation $1: z$ score weight or head circumference $=\frac{\text { observed value }- \text { median of refrence population }}{\text { standard diviation of refrence population }}$
equation 2: $z$ score length $=\frac{(\text { length } / M)^{2}}{L * s}$
equation $3: z$ score weight for length $=\frac{(\text { weight } / M)^{2}-1}{L * s}$
equation $4: z$ score $>-2:$ no stunting
equation $5:-3<z$ score $\leq-2:$ modrate stunting
equation $5: z$ score $\leq-3:$ sever stunting
equation $6: z$ score $>1.6:$ over weight
equation $7:-1.6<z$ score $\leq 1.6:$ healthy weight
equation $8:-2<z$ score $\leq-1.6:$ under weight
equation $9:-3<z$ score $\leq-2$ : modrate wasting
equation $10: z$ score $\leq-3:$ sever wasting

\section{Results}

From 1336 children, (47.6\%) 636 were girls and (52.4) 700 were boys.

Table 1 shows the mean distribution, standard deviation, and the differences in weight, height, and head circumference of the children under study based on gender differences.

Average difference of the weight of boys and girls at early days of birth was only 67 grams. With the increase in age this difference showed also an increasing trend, insofar as from the first month to the 24th month, the average weight difference between boys and girls was about 350 grams. Changes in the midrange and interquartile range between the boys and girls in the first few months started with a soft trend and continued with a relatively constant $400 \mathrm{~g}$ difference from the fourth month onwards.

Average difference in height between male and female children was $0.36 \mathrm{~cm}$ at birth. In the whole course of two years period, boys' height increased by $1.2 \mathrm{~cm}$ as compared to that of the girls. Although the average height at birth was equal in both male and female groups, the average height of boys retained its $1 \mathrm{~cm}$ superiority up to 24 months from the first month onward.

Average head circumference of the studied children at birth showed a difference of $0.37 \mathrm{~cm}$ in boys as compared to the girls. As the children's age increased, this difference in growth showed an increasing trend, insofar as from the first month to the 18 th month, the difference continued with $0.7 \mathrm{~cm}$ superiority of boys as compared to the girls.

By and large and in view of gender comparison, despite the closeness of weight, height and head circumference differences between boys and girls at birth, their growth difference over the two-years period substantiates boys' superiority.

According to the findings of Table 2, the prevalence of low weight at birth in both genders was $3.9 \%$, and this ratio for the boys and girls under study was respectively 3.8 and 3.9. Nevertheless, at the end of two years, the weight ratio in both genders got fixed at 3.8, but this stability was due to an increase in the prevalence of underweight for male infants $(4.8 \%)$ and a decrease in the prevalence of underweight among female infants (3.14\%).

According to the findings of table 3 , the prevalence of wasting at-birth has been estimated to be $18.7 \%$ in boys and $7.7 \%$ in girls. In view of the severity, $12 \%$ of boys suffered minor wasting (weight loss), $4.86 \%$ suffered moderate wasting and $1.4 \%$ suffered severe weight loss. The corresponding numbers in girls for the mentioned indicators were respectively 3.5, 2.2 and 1.8 percent. To put it otherwise, this index was better for girls than boys at all levels at birth. In both genders, the gradient trend of wasting changes in view of different months of child growth shows a decreasing trend, though the rate of these changes in boys is more steep. In other words, the rate of improvement of weight index in boys during the two-years period is more desirable than the girls who are involved in the study. At 2 years, the prevalence of overall wasting in boys was estimated to be $16.8 \%$ and in girls $8.47 \%$.

The prevalence of stunting among boys and girls were estimated to be respectively 7 and $5.35 \%$. Minor stunting in males and females was respectively 5.5 and 3.6 , while severe stunting was respectively $1.4 \%$ and $1.3 \%$. Generally speaking, stunting among boys is more prevalent than girls. The process of minor and severe changes in stunting in both boys and girls has shown an increasing trend over the course of two years. It is worth noting that the increase in gradient in boys is more steep as compared to girls. Said differently, severe stunting in boys gets worsened with age increase. 
The prevalence of microcephaly (minor and severe) at birth were estimated to be respectively 0.8 and $1.73 \%$ for boys and girls. At the end of two years, the prevalence of microcephaly for boys and girls was estimated to be 1.28 and 0.78 percent. To state the matter in different words, this percentage showed increase in boys and decline in girls.

Trend charts of weight, height, and head circumference indices for age in both male and female sexes do not show any significant difference. Although the wider base of the charts for boys geneder group demonstrates more heterogeneity in weight and height for male infants. On the other hand, heterogeneity and instability of measurements in head circumference in the female gender group are more sensible than that of boys.

During the whole period of monitoring, the average weight, height and head circumference in boys were more than girls.

The weight difference for age in boys as compared to girls began with 67 grams at birth and this process continued with a steep trend line up to four months and after then it continued with a more level tone until the end of two years.

The difference of average height for age at birth started with a difference of $0.37 \mathrm{~cm}$ between boys and girls and reached the heighest degree of difference within five-months with a steep trend line, then the process of difference reduction continued up until 15 months and from 15 months to the end of two years the increasing trend did start again.

The average difference of head circumference for age at birth showed a $0.36 \mathrm{~cm}$ difference, and this trend continued up to six months and after undergoing through a mild process the same trend continued from six months to fifteen months, and from 18 months onward, the changes in the average head circumference speeded up. By fitting the third degree model, the average of head circumference was predicted from 18 months to the end of two years, that indicates an increase in the average of head circumference of boys as compared to girls.

During the whole course of monitoring, weight loss in boys was more prevalent than girls. While early postnatal wasting in male infants is more than that of female infants (the male to female ratio of wasting is 2.4), this gap has declined up to 15 months (at 12 months, the male to female ratio of wasting is 2.3 ), insofar as this difference at 24 months reached its minimum possible (male to female ratio of wasting is 1.9).

During the whole course of monitoring, weight loss in boys was more prevalent than girls. While early postnatal wasting in male infants is more than that of female infants (the male to female ratio of wasting is 2.4), this gap has declined up to 15 months (at 12 months, the male to female ratio of wasting is 2.3 ), insofar as this difference at 24 months reached its minimum possible (male to female ratio of wasting is 1.9).

During the entire course of growth, short stature in boys was more prevalent than girls. Indicator gap ratio at birth (male to female ratio) was 1.3. This ratio showed a continuous increase in the course of the year, insofar as at 7 months the male to female ration of short stature reached 1.9. After a slight decrease, this index took an increasing trend again and at the end of two years, the ratio of short male infants as compared to female infants reduced to 1.6 .

During the whole course of growth, microcephaly was more prevalent among boys than girls. The early postnantal microcephaly was lower in boys as compared to girls. The gap in the percentage of microcephaly as separately for male and female infants has had an increasing trend up to seven months and has started to decline from nine months and continued its declining trend

\section{Discussion}

The standardized chart (Z score) for weight, height, and head circumference indices in both groups showed the same pattern, which did not show a significant difference with the standardized child development pattern (WHO). Growth trend based on three indicators of average weight, height and head circumference for age in all periods of measurement showed better growth in boys than girls. (Table 1, Chart 1). According to the indicators of estimation of prevalence of underweight, wasting, short stature and microcephally, in all periods of monitoring, the male infants were is undesirable conditions as compared to female infants (Tables 2-5 and Charts 2-6).

Research findings indicated the proximity of the weightfor age index at birth in male and female infants studied in this research (Chart 1). To put it otherwise, no relationship has been observed between gender and birth weight. In the study conducted by Tusi et al., gender did not have any significant relationship with birth weight, height and head circumference. Furthermore, in the study conducted by Ali Malayeri (Jodipour) et al., in Sistan, the weight difference between male and female newborns was not statistically significant $[13,15]$. These findings are not in line with WHO reports and several other studies that suggested that female newborns were at the risk of underweight $[16,17]$.

As the age increased, the gradient of this index increased more and more between boys and girls, insofar as in a relatively uniform manner at all times, the average weight of boys was higher than that of girls. This finding is consistent with the results of several other studies [18, 19, 20, 21]. It is important to note that in comparison of groups and populations, the reliance on the average index for comparative remarks is confronted with certain problems. Although the average weight of male infants in all periods has been higher than that of the girls, underweighted male infants in all stages of growth have been more than the female underweighted infants, and this shows the practical nature of frequency indicators compared to average based indices in population comparison.

While the rate gradient of changes in male underweighted infants was steeper in all points of the two years period as compared to female infants, the gradient of the changes in the average weight of the boys was the same in comparison to the girls in the whole follow-up period. Ayatollah et al., have studied the growth trend of 256 newborns and reported the highness of the growth rate of male infants as compared to female infants in the first year and the uniformity of growth rate from the first year onwards. In an alternative study the increasing trend in weight in ten days and thirty days was related to maleness [9, 19].

The average height for age of newborn infants showed a less than half a centimeter difference in the male newborns as compared to baby girls. In several other studies, the neonatal height of male newborns was reported to be higher than girls $[14,22,23]$. With the increase in the age of infants, this growth 
difference showed an increasing trend, insofar as from 1 month to 24 months, the height difference of $1 \mathrm{~cm}$ continued with male infants' superiority over the female infants. Generally speaking, the boys' height increase as compared to girls is significantly different over the entire two-years period of suckling. The current finding is consistent with the results of other studies in the later stages of the development of children and adolescents, including a longitudinal study (cohort study) in a region of Korea on a group of children of 6 years old and up the average of this index was higher in boys than in girls to the ultimate height growth (173.5 and $160.5 \mathrm{~cm}$ respectively), which is consistent with the results of the cross-sectional study of 2007 in Korea [24, 25]. In all postnatal growth stages the average height of boys has been one $\mathrm{cm}$ more than that of girls. On the other hand, despite the fluctuation in the ratio of weight loss in different periods, in all courses, the ratio of underweighted male children was higher than that of the girls.

The average of head circumference for age at birth showed a slight difference in male newborns compared to the female newborns. This finding is consistent with the results of several other studies and this difference has been statistically significant in the study by Ali Malayeri et al. [14, 23, 26]. As the age of children increased, this growth difference showed an increasing trend, insofar as after the first month to one and half years, the difference in growth between male suckling infants as compared to the female ones continued with a stable height of $0.7 \mathrm{~cm}$. Many other similar studies have also confirmed this finding $[18,19,20,21]$.

Generally speaking, despite the closeness of weight, height and head circumference difference between male and female newborn infants, their growth difference over the two-years period has recorded the superiority of boys. Some of the WHO standard growth charts show the difference between the two genders $[18,19,20,21]$. But the noticeable point in this study is the persistence and stability of significant differences in the indicators discussed as regards boys compared to girls and the increase in the difference gradient from 9 months onwards. In Iran the mother are advised to use supplement nutrition from 4-6 months, and more than $90 \%$ of infants will benefit from supplement from about six months. This shows the correlation between the period of using supplement and the increase in the difference in growth rates. The similarity of temporal and spatial conditions provides researchers little justification for justifying the observed pattern. In other words, unsystematic attention to child nutrition, especially male infants, in the family, and even lack of attention to childhood care, can explain the wide range of changes and differences observed if they do not explain all the differences.

The findings of the current research showed that the prevalence of underweight for age at birth was nearly four percent in both sexes, and this ratio was almost the same for male and female newborns, which is consistent with the results of the Ayatollahi's study that was conducted in Maku (3.9\%), but it is inconsistent with the study that has been conducted by Ali Malayeri et al. both in frequency $(9.3 \%$ ) and in gender (male and female, respectively $10.9 \%$ and 7.7\%). Moreover, according to the UNICEF 2013 report, this indicator is of 15 percent prevalence in the world in under 5 age group and reaches 25 percent in South Asian countries [6, 9, 14].

Although at the end of two years, the ratio of underweight for the whole sample under study remained almost constant, but this stability was not associated with maintaining the pattern of gender distribution at birth, insofar as the percentage of underweight in male sucklings is increased, but declined in female infants. If we are supposed to interpret these changes in line with the previous discussion, this seems to be due to the improvement in the height growth of male infants as compared to the weight gaining of these children in comparison to girls.

According to wasting index (underweight for height), in the early days of birth, minor wasting in male newborns was about four times higher than girls. Moreover, in view of moderate and severe weight loss (wasting), the prevalence of these degrees of underweight in boys was about one and a half times higher than female infants. This finding is consistent with the results of several other studies [19,27], while the results of several other studies are contrary to this finding, e.g. in a study in the Gamb province of Nigeria, prevalence of weight loss was higher in girls as compared to boys (2.6 and 2), and severe wasting in both sexes was zero [21, 28].

The proportion of minor short stature at birth in male newborns was about one-and-a-half percent higher than girls. This index for severe stunting at birth was nearly equal in both genders. In other words, generally speaking, short stature in boys has been more prevalent than girls. This finding is consistent with some other studies, including the study that has been conducted by Zhank in Bangladesh. The prevalence of short stature at birth in boys (18\%) was higher than girls $(14 \%)[29,30]$.

The trend ofchanges in minor and severe stunting in all the infants under study during the two-years period has shown an increasing trend. The point that is noteworthy in this observation is that the gradient of increase in boys has been more as compared to girls. To put it otherwise, severe stunting was more prevalent in boys with higher age, and striking height changes in infants continued to show greater resistance to this point. The prevalence of short stature in this study is consistent with the results of the Nigerian study (the prevalence of moderate short stature in males and females were respectively $47 \%$ and $33 \%$, and severe short stature were $14 \%$ and $12 \%$ respectively) [28].

The prevalence of short stature in this study is consistent with the results of the Nigerian study (the prevalence of moderate stunting in male and female infants). However, since the index of stunting is more indicative of chronic malnutrition mainly due to micronutrient deficiencies, serious attention is needed to be paid to eliminating the effective factors such as socioeconomic, nutritional and environmental problems. In several studies, the main cause of short stature has been traced back to poverty, and in the next stages, to inattention, parasitic infections and genetic factors [31, 32]. In a study the positive and direct impact of consumption of the iron supplement has been shown to increase height lengths after 6 months [21].

The percentage of smaller head circumference at birth in both genders has been less than 1 percent, and this trend remained relatively constant during the course of the growth. To state the matter differently, the index showed a desirable status in the population under study. In a study, the direct effect of breastfeeding on the proper growth of the head has been shown [21]. Although, no significant difference was seen at birth in the sextuple indexes (weight, height, head circumference, underweight, wasting and stunting) between boys and girls, and though the average weight, height, and head circumference indices were better in boys as compared to girls, but over a two-years period, the prevalence of underweight, wasting and short stature was higher in boys than in girls, and this is a remarkable point that is not consistent with presuppositions of of better male infants' growth indices as compred to those of the female

Page 5/11 
infants. To the state the matter in different words, against the existing expectations, the status of growth indices in boys is worse than those of girls, and this issue deserves to be taken into account in view of the justce in sexual health. The family structure in Iran, Iranian boys' responsibilities in the family system, and finally the increased prevalence of these indicators in male group, double the necessity of adopting preventive approaches to children's nutritional care. It seems that the change in Iranian families general attitude as regards preferring to have girls instead of boys is one of the most important justifications for this difference in the growth trend. Another point that might be useful in justifying this finding is that, despite the attention that is paid by families to boys within the families of male newborns, the family's cultural, social and economic conditions are more effective than the parents' desire in infants growth. This is merely a theory that the present study does not provide strong evidence of its confirmation or rejection, and it requires a special study to be designed so as to clarify the position of the parents' desire to change versus the family's scientific ability to change their child's development. Moreover, the results of the current research serve as a warning to the effect that the emphasis on mental beliefs (a health justice gap with male gender superiority to the girl) need to be replaced with the approach of "analysis of justice in health based on evidences", so that as a result of mere attention based on theoretical foundations of policy makers, the opposite group (boys) do not suffer damages following the theoretization. We should not forget that two important goals (goals 3 and 4 ) of the 8th MDG2015 are child health and gender equality [33]. Then, though the families need to increase their awareness and knowledge in order to change their attitudes, beliefs and practices, there is still a more urgent thing here, i.e. having clear evidences of the existence of a gap orthe superiority of a particular sexual group. by probable outliers, equality of variances, and the assumption of normal distribution of data, such as multivariate regression analysis, and so on and so forth.

\section{Conclusion}

While the primary and subjective theories induce the worse growth indices of girls, the findings of the present study suggest a different truth (the prevalence of worser growth indices in male infants). The family structure in Iran and the studied province, the male responsibilities in the family system, along with the higher percentage of undesirable growth indicators in the male gender group, increase the need for attention and review of preventive programs, especially in children's nutritional care. The skewness of the distribution of raw numbers of weight, height, and head circumference based on age, as well as the presence of probable outliers in the two ends of studied distributions are among the analytic weaknesses based on the procedural comparison of the developmental indices. Therefore, it is recommended that in future studies other researchers use statistical methods that are not affected

\section{Abbreviations}

LBW: Low Birth Weight, MDG: Millenium Development Goal ,WHO: World Health Organization

\section{Declarations}

\section{*Ethics approval and consent to participate}

Ethics approval and consent to participate: Study protocol was approved by the Ethic Committee of the School of Public Health,Yasuj University of medical sciences (Ir.yums.REC.1394.78). informed consent form was obtained from all mothers

\section{*Consent for publication}

informed consent was obtained from all mothers. This Informed Consent Form had two parts:

- Information Sheet (to share information about the study)

- Certificate of Consent (for signatures if participants choose to participate)

\section{*Availability of data and material}

not available

\section{*Competing interests}

none declared

\section{*Funding}

This work was funded by deputy of research of yasuj university of medical sciences.sciences

\section{*Authors' contributions}

Azizollah Pourmahmoudi, conceived and designed the original study.

Ali Mousavizadeh, conducted the analysis of data and drafted the manuscript.

Maryam dastoorpoor, coordinated the study and collected data.

Zibane Tabeshfar, coordinated the study and collected data.

Mahboobe Hosseinikia, coordinated the study and collected data 
Raana kousari, searched databases, reviewed previous studies, refrences.

\section{*Acknowledgements}

This research was supported by deputy of research of yasuj university of medical sciences. We thank our colleagues from department of nutrition and food sciences who provided insight and expertise that greatly assisted the research

*Authors' information (optional)

\section{Azizollah Pourmahmoudi ${ }^{1}$, Ali Mousavizadeh ${ }^{\star 2}$, Maryam dastoorpoor ${ }^{3}$, Zibane Tabeshfar ${ }^{4}$, Mahboobe Hosseinikia ${ }^{5}$, Raana kousari ${ }^{6}$}

1-Ph.D in Nutrition sciences, Determinants of Nutrition, School of Health, Yasuj University of Medical Sciences, Yasuj, Iran.Email: pourmahmoudi@gmail.com 2- PhD in Epidemiology, Social Determinants of Health Research Center, Yasuj University of Medical Sciences Yasuj, Iran. (corresponding author) Email: mousavizadeh_a@yahoo.com

3-Department of Epidemiology and Biostatistics, Menopause Andropause Research Center, Ahvaz Jundishapur University of Medical Sciences, Ahvaz, Iran 4- Msc of epidemiology, Social Determinants of Health Research Center, Yasuj University of Medical Sciences Yasuj, Iran.

5- Msc of nutrition sciences,Determinants of Nutrition, School of Health, Yasuj University of Medical Sciences, Yasuj, Iran.Email: m.hosseinikia@yahoo.com 6- Msc in Medical Library \& Information science, Dezful University of Medical Sciences, Dezful, Iran. Email: raana.kousari@gmail.com

corresponding author:Ali Mousavizadeh, PhD in Epidemiology, Social Determinants of Health Research Center, Yasuj University of Medical Sciences Yasuj, Iran. Email:mousavizadeh_a@yahoo.com

Conflict of interests: The authors declare that they have no conflict of interests.

\section{References}

1. Amusu AM, Degun AM, Atulomah NO, Olanrewaju MF. A Studyof the nutritional status of under-5 children of low-incomeearners in a South-Western Nigerian Community. J Biol Sci 2011; 3:3 78-585.

2. De Onis M, Onyango A, Borghi E, Siyam A, Blössner M \& Lutter C. Worldwide implementation of the WHO child growth standards. Public health nutrition, 2012; 15(09), 1603-1610.

3. De Onis M, Blo“ssner M, Borghi E, Rongillo E, Morris R, Estimates of global prevalence of childhood underweight in 1990 and 2015. Jama, 2004; 291(21): p. 2600-2606.

4. Asadi-Lari M, , Sayyari AA, Akbari ME, Gray D.Public health improvement in Iran-lessons from the last 20 years. Public health, 2004. 118(6): p. $395-402$.

5. Khosravi A1, Taylor R, Naghavi M, Lopez AD.Mortality in the islamic republic of Iran, 1964-2004. Bulletin of the World Health Organization, 2007; 85(8): p. 607-614.

6. The key figures and statistics on nutrition, are derived from the latest UNICEF nutrition report in 2013: " Improving Child Nutrition: The achievable imperative for global progress."

7. Deputy of Health of Yasouj University of Medical Sciences. , Department of medical statistics

8. Fenton T.R. and Sauve R.S. Using the LMS method to calculate z-scores for the Fenton preterm infant growth chart. Eur J Clin Nutr, 2007; 61(12): p. 13805.

9. Ayatollahi S.M, Haem E and Sharafi Z. Growth Velocity of Infants From Birth to 5 Years Born in Maku, Iran. Glob J Health Sci, 2015; 8(2): p. 56-63.

10. Ayatollahi S.M, Sharafi Z and Haem E. Child Weight Growth Chart and Its Associated Factors in Birth Cohort of Maku Using a Growth Curve Model and LMS Method. Glob J Health Sci, 2015; 7(6): p. 181-6.

11. An evaluation of infant growth: the use and interpretation of anthropometry ininfants. WHO Working Group on Infant Growth. Bull World Health Organ, 1995; 73(2): p. 165-74.

12. Albusta N, Almarzooq R, Board-Pediatrics A. Evaluation of the Physical Growth Parameters on the Developmental Outcome of Children below Six Years of Age. Bahrain Medical Bulletin. 2019 Mar;41(1).

13. Toosi M, Akbarzadeh M, Zare N.. Relationship between maternal hematologic concentration and BMI in primiparous women on some physiological parameters in neonates. Sci Jlran Blood Transfus Organ 2013; 10 (1): 77-85.

14. Judipour Z, Alimalayeri F, Bagheri S, Bazzi A, Judipour M, Judipour M. A Survey on Anthropometric Parameters of Neonates at Birth and Some Effective Demographic Factors in Sistan Region. IUMS J 2015;23(4):106-13.

15. Alur P. Sex Differences in Nutrition, Growth and Metabolism in Preterm Infants. Frontiers in Pediatrics. 2019;7:22.

16. Jensen EA, Demauro SB, Kornhauser M, Aghai ZH, Greenspan JS, Dysart KC. Effects of multiple ventilation courses and duration of mechanical ventilation on respiratory outcomes in extremely low birth weight infants. JAMA Pediatr 2015; 28:1-7.

17. Walker DM, Tolentino VR, Teach SJ. Trends and challenges in international pediatric emergency medicine. Curr Opin Pediatry2007;19:247-52. 
18. Ghahremani F, Hoseini F, Ghobadi Dashdbi K. Growth indicators and related factors in children under 6 years in Shiraz city in 2008. J Jahrom Univ Med Sci. 2012; 10(3): 54.

19. Aturupane H, Deolalikar AB, Gunewardena D. The determinants of child weight and height in Sri Lanka: A quantile regression approach. Working Paper Series. World Institute for Development Economic Research. 2008.

20. Masiye F, Chama C, Chitah B, Jonsson D. Determinants of child nutritional status in Zambia: An analysis of a national survey. Zambia Soc Sci J. 2010; 1(1): 29-42.

21. Hajiaghamohammadi N, Sedehi M, Kheiri S, Khoshdel A. Influentialfactors on growth parameters in infants using quantile regression analysis. J Shahrekord Univ, Med Sci. 2015; 17(2): 7-16.

22. Slavens BA, Schnorenberg AJ, Aurit CM, Tarima S, Vogel LC, Harris GF. Biomechanics of pediatric manual wheelchair mobility. Front Bioeng Biotechnol 2015; 10(3):137.

23. Ayatollahi SMT, Rafiei M. Supine length weight and head circumference at birth in central Iran. Early Child Dev Care 2007; 177: 255-58.

24. Chae H. W., Suh I, Kwon A R, Kim YJ, Kim YH, Kang DR et al. Longitudinal Standards for Height and Height Velocity in Korean Children and Adolescents: The Kangwha Cohort Study. J Korean Med Sci 2013; 28(10): 1512-1517.

25. Moon JS, Lee SY, Nam CM, Choi JM, Choe BK, Seo JW, et al. 2007 Korean National Growth Charts: review of developmental process and an outlook. Korean J Pediatr 2008; 51: 1-25.

26. Ayatollahi SMT, Rafiei M. Supine length weight and head circumference at birth in urban Arak areas and factors affecting them. Med J Islamic Rep Iran 2006;19:363-6.

27. Medhin G, Hanlon C, Dewey M, Alem A, Tesfaye F, Worku B, et al. Prevalence andpredictors of undernutrition among infants aged six and twelve months in Butajira, Ethiopia: the P-MaMiE Birth Cohort. BMC Public Health. 2010; 10(1): 27.

28. Mela Danjin, Nasiba U Dawud.A survey of nutritional status of children 0-12 months in specialist hospital Gombe,Nigeria.Journal of Health and Research, 2017; 2(2): 109-114.

29. Zhang Y, Zhou J, Niu1 F, Jeffrey R. Donowitz, Rashidul Haque, William A. et al.Characterizing early child Growth patternsof height-for-age in an urban slum cohort of Bangladesh with functional principal component analysis. 2017; BMC Pediatrics, 17:84.

30. Danjin M, Adamu S, Ribadu SB, Lekke FY, Garba AU, Adamu D.Anthropometric assessment of nutritional status of school children (aged5-15) in public primary schools in Gombe Metropolis, Nigeria. NursMidwifery Counc Niger Res J 2011;1:76-82.

31. National Population Commission (NPC) [Nigeria] and ICF Macro.Nigeria Demographic and Health Survey (NDHS) 2008. Abuja,Nigeria: National Population Commission and ICF Macro. Nutritionof Children and Adults; 2009. p. 163-85.

32. Mamadou B, Dwebel TF. Persistent hunger; perspectives onvulnerability, famine and food security in Sub-Saharan Africa. AnnuAnthropol Rev 2006;35:521-38.

33. Sbmu.ac.ir > uploads >. Millennium Development Goals 2015.

\section{Tables}

Table 1: Main Descriptive Statistics of weight $(\mathrm{mg})$, length $(\mathrm{cm})$ and head circumferrence $(\mathrm{cm})$ in under 24 month Childs in k\&b province south west of Iran 2015 by month and sex (700 male, 636 female). 


\begin{tabular}{|c|c|c|c|c|c|c|c|c|c|c|}
\hline \multirow[t]{3}{*}{ Month } & \multirow[t]{3}{*}{ Sex } & \multicolumn{3}{|c|}{ WEIGHT(gr) } & \multicolumn{3}{|c|}{ LENGTH(cm) } & \multicolumn{3}{|c|}{ Head CIRCUMFERENCE(cm) } \\
\hline & & Mean & S-D & Mean & Mean & S-D & Mean & Mean & S-D & Mean \\
\hline & & & & Difference & & & Difference & & & Difference \\
\hline \multirow[t]{2}{*}{0} & Male & 3125.00 & 498.3 & \multirow[t]{2}{*}{66.7} & 49.834 & 2.335 & \multirow[t]{2}{*}{0.37} & 34.917 & 1.388 & 0.377 \\
\hline & female & 3058.30 & 477.7 & & 49.468 & 2.412 & & 34.540 & 1.395 & \\
\hline \multirow[t]{2}{*}{1} & Male & 4508.10 & 703.3 & \multirow[t]{2}{*}{204.5} & 54.675 & 2.568 & \multirow[t]{2}{*}{0.56} & 37.578 & 1.612 & 0.552 \\
\hline & Female & 4303.60 & 622.7 & & 54.114 & 2.504 & & 37.026 & 1.326 & \\
\hline \multirow[t]{2}{*}{2} & Male & 5484.60 & 730.1 & \multirow[t]{2}{*}{309.1} & 58.181 & 2.692 & \multirow[t]{2}{*}{0.99} & 39.193 & 1.426 & 0.69 \\
\hline & Female & 5175.50 & 669.5 & & 57.192 & 2.591 & & 38.503 & 1.368 & \\
\hline \multirow[t]{2}{*}{4} & Male & 6905.40 & 907.1 & \multirow[t]{2}{*}{395.7} & 63.827 & 2.827 & \multirow[t]{2}{*}{1.87} & 41.518 & 1.530 & 0.786 \\
\hline & Female & 6509.70 & 873.2 & & 61.954 & 2.804 & & 40.732 & 1.403 & \\
\hline \multirow[t]{2}{*}{6} & Male & 7825.00 & 961.6 & \multirow[t]{2}{*}{399.7} & 66.848 & 2.888 & \multirow[t]{2}{*}{1.25} & 43.155 & 1.444 & 0.758 \\
\hline & Female & 7425.30 & 959.7 & & 65.598 & 2.792 & & 42.397 & 1.351 & \\
\hline \multirow[t]{2}{*}{7} & Male & 8239.40 & 985.5 & \multirow[t]{2}{*}{403.6} & 68.834 & 2.995 & \multirow[t]{2}{*}{1.18} & 44.033 & 1.390 & 0.718 \\
\hline & Female & 7835.80 & 986.6 & & 67.658 & 3.065 & & 43.315 & 1.295 & \\
\hline \multirow[t]{2}{*}{9} & Male & 8790.90 & 1009.5 & \multirow[t]{2}{*}{411.5} & 71.463 & 3.117 & \multirow[t]{2}{*}{1.16} & 45.07 & 1.343 & 0.769 \\
\hline & Female & 8379.40 & 1029.6 & & 70.299 & 3.132 & & 44.301 & 1.361 & \\
\hline \multirow[t]{2}{*}{12} & Male & 9483.40 & 1126.6 & \multirow[t]{2}{*}{441.6} & 74.889 & 3.235 & \multirow[t]{2}{*}{1.085} & 46.197 & 1.320 & 0.81 \\
\hline & Female & 9041.80 & 1111.9 & & 73.802 & 3.188 & & 45.387 & 1.368 & \\
\hline \multirow[t]{2}{*}{15} & Male & 10094.00 & 1183.0 & \multirow[t]{2}{*}{419.5} & 77.880 & 3.464 & 0.91 & 47.109 & 1.318 & 0.837 \\
\hline & Female & 9674.50 & 1166.5 & & 76.968 & 3.380 & & 46.272 & 1.106 & \\
\hline 18 & Male & 10691.00 & 1280 & 444 & 80.843 & 3.798 & 0.81 & 47.932 & 1.347 & 0.793 \\
\hline & Female & 10247.00 & 1282 & & 80.038 & 3.610 & & 47.139 & 1.488 & \\
\hline 24 & Male & 11500.00 & 1404 & 387 & 83.942 & 4.238 & 3.51 & * & * & * \\
\hline & Female & 11113.00 & 1432 & & 82.434 & 4.001 & & * & * & * \\
\hline
\end{tabular}

Table 2: Frequency distribution of weight indicators for age in children under two years based on gender differences and various months of care in Kohgiluyeh and Boyer Ahmad in 2015.

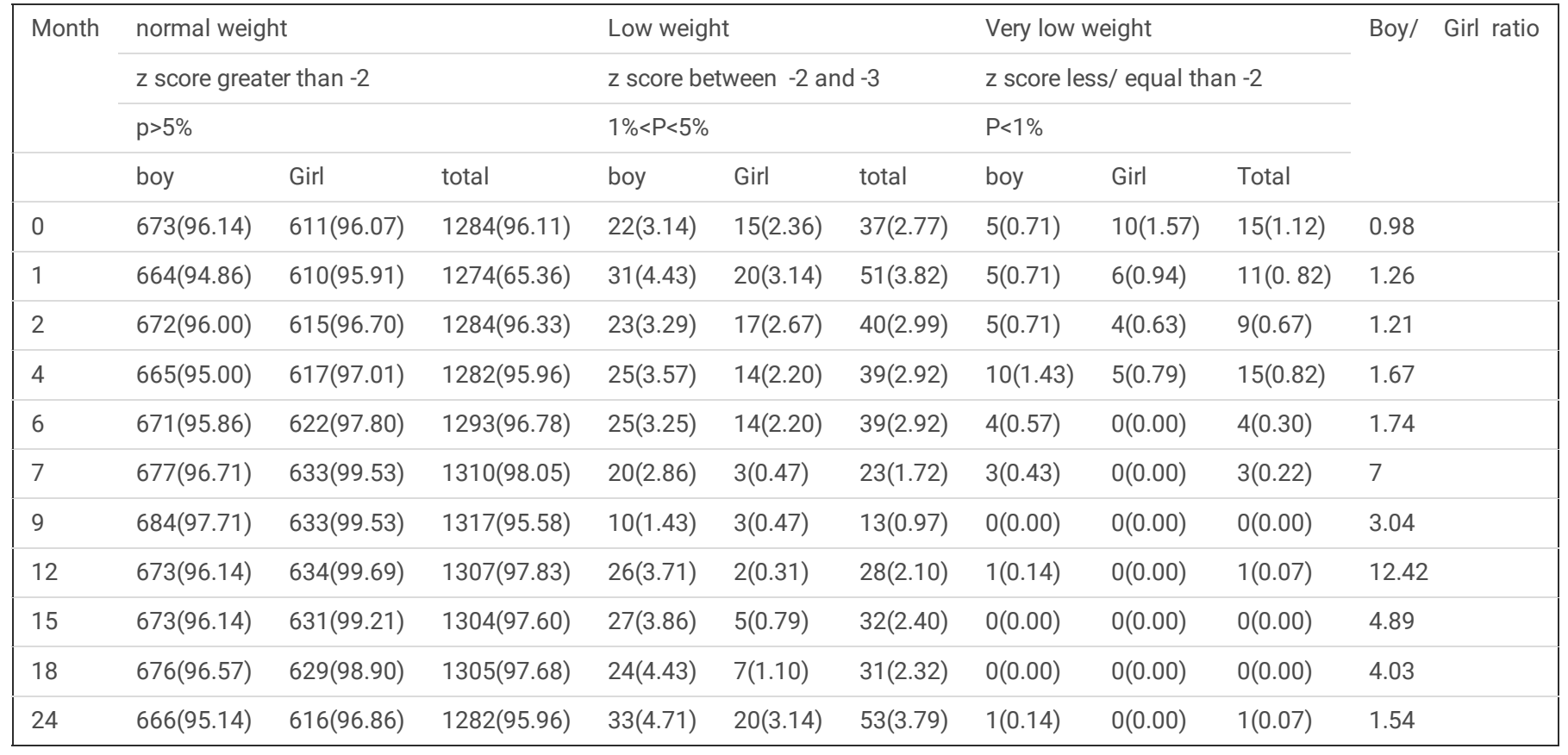


Table 3: Frequency distribution of height indicators for age in children under two years based on gender.

\begin{tabular}{|c|c|c|c|c|c|c|c|c|c|c|c|c|}
\hline \multirow{3}{*}{ month } & \multicolumn{3}{|l|}{ Obese } & \multicolumn{3}{|c|}{ Mild wasting } & \multicolumn{3}{|c|}{ Moderate wasting } & \multicolumn{3}{|c|}{ Sever wasting } \\
\hline & equal or $C$ & eater than & & Between -2 & to -1.6 & & Between - & to -2 & & Less than & & \\
\hline & boy & girl & total & boy & girl & total & boy & girl & total & boy & Girl & Total \\
\hline 0 & $15(2.14)$ & $12(1.89)$ & $27(2.02)$ & $85(12.14)$ & $48(3.59)$ & 133(9.96) & $34(4.86)$ & $14(2.20)$ & $48(3.59)$ & $10(1.43)$ & $12(1.89)$ & $22(1.65)$ \\
\hline 1 & $39(5.57)$ & $38(5.97)$ & $77(5.76)$ & $29(4.14)$ & $13(0.97)$ & $42(3.14)$ & $31(4.43)$ & $24(3.77)$ & $55(4.12)$ & $10(1.43)$ & $10(1.57)$ & $20(1.50)$ \\
\hline 2 & $27(3.86)$ & $27(4.25)$ & $54(4.04)$ & $33(4.71)$ & $20(1.50)$ & $53(3.97)$ & $27(3.86)$ & $20(3.14)$ & $47(3.52)$ & $15(2.14)$ & $10(1.57)$ & $25(1.87)$ \\
\hline 4 & $28(4.00)$ & $36(5.66)$ & $64(4.79)$ & $18(2.57)$ & $21(1.57)$ & $39(2.92)$ & $42(6.00)$ & $28(4.40)$ & $70(5.24)$ & $11(1.57)$ & $8(1.26)$ & $19(1.42)$ \\
\hline 6 & $30(4.29)$ & $45(7.08)$ & $75(5.61)$ & $22(3.14)$ & $25(1.87)$ & $47(3.52)$ & $32(5.57)$ & $24(3.77)$ & $56(4.19)$ & $11(1.57)$ & $2(0.31)$ & $13(0.97)$ \\
\hline 7 & $37(5.29)$ & $41(6.45)$ & $78(5.84)$ & $21(3.00)$ & $22(1.65)$ & 439(3.22) & $29(4.14)$ & $17(2.67)$ & $46(3.44)$ & $5(0.71)$ & $1(0.16)$ & $6(0.45)$ \\
\hline 9 & $30(4.29)$ & $34(5.35)$ & $64(4.79)$ & 23(3.29) & $17(1.27)$ & $40(2.99)$ & $34(4.86)$ & 11(1.73) & $45(3.37)$ & $3(0.43)$ & $1(0.16)$ & $4(0.30)$ \\
\hline 12 & $44(6.29)$ & $33(5.19)$ & $77(5.76)$ & $33(4.71)$ & $23(1.72)$ & $56(4.19)$ & $32(4.57)$ & $9(1.42)$ & 41(3.07) & $3(0.43)$ & $1(0.16)$ & $4(0.30)$ \\
\hline 15 & $36(5.14)$ & $31(4.87)$ & $67(5.01)$ & $34(4.86)$ & $22(1.65)$ & $56(4.19)$ & $34(4.86)$ & $16(2.52)$ & $50(3.74)$ & $3(0.43)$ & $1(0.16)$ & $4(0.30)$ \\
\hline 18 & $33(4.71)$ & $24(3.77)$ & $57(4.27)$ & $33(4.71)$ & $20(1.50)$ & $53(3.97)$ & $34(4.86)$ & 21(3.30) & $55(4.12)$ & $6(0.86)$ & $2(0.31)$ & $8(0.60)$ \\
\hline 24 & $18(2.57)$ & $13(2.04)$ & $31(2.32)$ & $66(9.43)$ & $27(2.02)$ & $93(6.96)$ & $47(6.71)$ & $37(5.82)$ & $84(6.29)$ & $5(0.71)$ & $4(0.63)$ & $9(0.67)$ \\
\hline
\end{tabular}

Table 4: Frequency distribution of height for weight indicators in children under two years based on gender differences in Kohgiluyeh and Boyer Ahmad province 2015.

\begin{tabular}{|c|c|c|c|c|c|c|c|c|c|c|}
\hline \multirow[t]{4}{*}{ month } & \multirow{2}{*}{\multicolumn{3}{|c|}{$\begin{array}{l}\text { Normal length } \\
\text { z score greater than }-2\end{array}$}} & \multicolumn{3}{|c|}{ Mild stunting } & \multicolumn{3}{|c|}{ Sever stunting } & \multirow[t]{4}{*}{ Boy / Girl ratio } \\
\hline & & & & z score bet & leen -2 and & & z score le & / equal th & $n-2$ & \\
\hline & \multicolumn{3}{|l|}{$p>5 \%$} & \multicolumn{3}{|l|}{$1 \%<P<5 \%$} & \multicolumn{3}{|l|}{$\mathrm{P}<1 \%$} & \\
\hline & boy & girl & total & boy & girl & total & boy & Girl & total & \\
\hline 0 & $651(93.00)$ & $602(94.65)$ & 1253(93.79) & $39(5.57)$ & $23(3.62)$ & $62(6.64)$ & $10(1.43)$ & 11(1.73) & 21(1.57) & 1.31 \\
\hline 1 & 657(98.86) & 617(97.01) & 1274(95.36) & $33(4.71)$ & $9(1.41)$ & $42(3.14)$ & $10(1.43)$ & $10(1.57)$ & $20(1.50)$ & 2.06 \\
\hline 2 & 648(92.57) & $608(95.60)$ & 1256(94.01) & $37(5.29)$ & 19(2.99) & $56(4.19)$ & $15(2.14)$ & $9(1.42)$ & $24(1.80)$ & 1.68 \\
\hline 4 & 639(91.29) & $592(9.08)$ & $1231(92.14)$ & $39(5.57)$ & $28(4.40)$ & $67(5.02)$ & $22(3.14)$ & $16(2.52)$ & $38(2.84)$ & 1.26 \\
\hline 6 & $620(88.57)$ & $587(92.30)$ & 1207(90.34) & $58(8.29)$ & $36(5.66)$ & $94(7.04)$ & $22(3.14)$ & $13(2.04)$ & $35(2.62)$ & 1.48 \\
\hline 7 & $650(32.86)$ & 611(96.07) & 1261(94.38) & $34(4.86)$ & $14(2.20)$ & $48(3.60)$ & $16(2.87)$ & $11(1.73)$ & $27(2.02)$ & 1.97 \\
\hline 9 & 631(90.14) & $590(92.77)$ & 1221(91.39) & $38(5.43)$ & $34(5.35)$ & 72(5.39) & $31(4.30)$ & 12(1.89) & $43(3.22)$ & 1.34 \\
\hline 12 & 646(92.29) & $601(94.50)$ & 1247(93.34) & $24(3.42)$ & $23(3.62)$ & $47(3.52)$ & $30(4.30)$ & $12(1.89)$ & $42(3.14)$ & 1.40 \\
\hline 15 & $592(84.57)$ & $585(91.98)$ & 1177(88.09) & $70(10)$ & $37(5.82)$ & $107(8.01)$ & $38(5.43)$ & $14(2.20)$ & $52(3.89)$ & 1.92 \\
\hline 18 & 61487.71) & 593(93.24) & 1207(90.34) & $45(6.43)$ & $31(4.87)$ & $76(5.69)$ & $41(5.86)$ & $12(1.89)$ & $53(3.97)$ & 1.82 \\
\hline 24 & $552(78.86)$ & $556(87.42)$ & 1108(82.93) & $83(11.86)$ & $51(8.01)$ & $134(10.03)$ & $65(9.29)$ & $29(4.56)$ & $94(7.04)$ & 1.68 \\
\hline
\end{tabular}

Table 5: Frequency distribution of head circumference indexes for age in children under two years based on gender differences and months of care in Kohgiluyeh and Boyer Ahmad 2015. 


\begin{tabular}{|c|c|c|c|c|c|c|c|c|c|c|}
\hline \multirow[t]{4}{*}{ month } & \multicolumn{3}{|c|}{ normal Head circumference } & \multicolumn{3}{|c|}{ mild microcephal } & \multicolumn{3}{|c|}{ overt microcephal } & \multirow[t]{4}{*}{ Boy / Girl ratio } \\
\hline & \multicolumn{3}{|c|}{ z score greater than -2} & \multicolumn{3}{|c|}{ z score between -2 and -3} & \multicolumn{3}{|c|}{ z score less/ equal than -2} & \\
\hline & \multicolumn{3}{|l|}{$p>5 \%$} & \multicolumn{3}{|c|}{$1 \%<P<5 \%$} & \multicolumn{3}{|l|}{$P<1 \%$} & \\
\hline & boy & girl & total & boy & girl & total & boy & girl & Total & \\
\hline 0 & 694(99.14) & 625(98.27) & 1319(98.73) & $5(0.71)$ & $6(0.94)$ & $11(0.82)$ & $1(0.14)$ & $5(0.79)$ & $6(0.45)$ & 0.49 \\
\hline 1 & 677(96.71) & 618(97.17) & 1295(96.93) & $17(2.43)$ & $11(1.73)$ & $28(2.10)$ & $6(0.86)$ & $7(1.10)$ & 13(0.97) & 1.16 \\
\hline 2 & 667(95.29) & 623(97.96) & $1290(95.56)$ & $30(4.29)$ & $9(1.42)$ & $39(2.92)$ & $3(0.43)$ & $4(0.63)$ & $7(0.52)$ & 2.30 \\
\hline 4 & $646(92.29)$ & $607(95.44)$ & 1253(93.79) & $32(4.57)$ & $24(3.77)$ & $56(4.20)$ & $22(3.14)$ & $5(0.79)$ & $27(2.02)$ & 1.69 \\
\hline 6 & $665(95.00)$ & $622(97.80)$ & 1287(96.33) & $21(3)$ & 11(1.73) & $32(2.40)$ & $14(2.00)$ & $3(0.47)$ & $17(1.27)$ & 2.27 \\
\hline 7 & $660(94.29)$ & 627(98.59 & 1287(96.33) & $34(4.86)$ & $7(1.10)$ & $41(3.10)$ & $6(0.86)$ & $2(0.31)$ & $8(0.60)$ & 4.06 \\
\hline 9 & $680(97.14)$ & $626(98.43)$ & 1306(97.75) & $18(2.57)$ & $9(1.42)$ & $27(2.02)$ & $2(0.29)$ & $1(0.16)$ & $3(0.22)$ & 1.81 \\
\hline 12 & 688(98.29) & $629(98.90)$ & 1317(98.58) & $10(1.43)$ & $4(0.63)$ & $14(1.04)$ & $2(0.29)$ & $3(0.47)$ & $5(0.37)$ & 1.56 \\
\hline 15 & 688(98.29) & $628(98.74)$ & 1316(98.50) & $9(1.29)$ & $4(0.63)$ & $13(0.97)$ & $3(0.43)$ & $4(0.63)$ & $7(0.52)$ & 1.37 \\
\hline 18 & 691(98.71) & 631(99.21) & 1322(98.95) & $8(1.14)$ & $3(0.47)$ & $11(0.82)$ & $1(0.14)$ & $2(0.31)$ & $3(0.22)$ & 1.64 \\
\hline
\end{tabular}

\section{Supplementary Files}

This is a list of supplementary files associated with this preprint. Click to download.

- supplementary.pdf 